\title{
Praktik signifikasi atas transformasi pelayanan referensi di Perpustakaan Universitas Indonesia
}

\author{
Indira Irawati \\ Program Studi Ilmu Perpustakaan dan Informasi, Universitas Indonesia \\ Jl. Margonda Raya, Pondok Cina, Kecamatan Beji, Kota Depok, Jawa Barat, 16424 \\ Email: indira20@ui.ac.id
}

Received: March 2020; Accepted: October 2020; Published: December 2020

\begin{abstract}
The transformation of reference services in academic libraries in the era of information technology has a significant impact on librarians. Librarians need to address transformation properly to design the right services. The University of Indonesia (UI) library has undergone this transformation since a decade ago and continues to adapt to existing developments. Various service concepts were developed to suit users' demands, including by providing online-based services and utilizing social media to communicate with users. This study aimed to explore how reference librarians interpreted this transformation and what they should do. The research method used qualitative methods with the phenomenological method narrated descriptively. The research informants consisted of 13 librarians and seven reference librarians. Data analysis showed that librarians'significance for transforming reference services resulted in 4 important themes that were interpreted as influencing their work as reference librarians. The four themes were digital-based library services, expansion of access, policy, and promotion. This research concludes that users and librarians' practice of significance for the transformation of reference services results in the digital libraries' concept, which requires expansion of access, relevant policies, and social media optimization for service promotion. The practice of significance related to communication patterns with reference users in the digital era effectively uses email and chatting on the WhatsApp application.
\end{abstract}

Keyword: Reference services; Academic library; Reference services transformation; Practice of signification

\begin{abstract}
Abstrak
Transformasi pelayanan referensi perpustakaan akademik di era teknologi informasi berdampak besar bagi pustakawan. Pustakawan perlu menyikapi transformasi dengan tepat agar dapat merancang pelayanan yang tepat. Perpustakaan Universitas Indonesia (UI) telah mengalami transformasi tersebut sejak satu dekade lalu dan terus berupaya menyesuaikan diri dengan perkembangan yang ada. Berbagai konsep pelayanan dikembangkan agar sesuai dengan tuntutan pengguna, antara lain dengan penyediaan pelayanan berbasis online dan memanfaatkan sosial media sebagai sarana komunikasi dengan pengguna. Penelitian ini bertujuan untuk menggali dan mengetahui bagaimana pustakawan referensi memaknai transformasi tersebut dan apa yang harus mereka lakukan. Metode penelitian menggunakan metode kualitatif dengan metode fenomenologi yang dinarasikan secara deskriptif. Informan penelitian terdiri dari 13 orang pengguna dan 7 orang pustakawan referensi. Analisis data menunjukkan bahwa signifikasi pustakawan atas transformasi pelayanan referensi menghasilkan 4 tema penting yang dimaknai sebagai hal yang memengaruhi pekerjaan mereka sebagai pustakawan referensi. Empat tema tersebut antara lain, pelayanan perpustakaan berbasis digital, perluasan akses, kebijakan, dan promosi. Kesimpulan penelitian adalah praktik signifikansi oleh pengguna dan pustakawan atas transformasi pelayanan referensi menghasilkan konsep digital library, yang memerlukan perluasan akses, kebijakan yang relevan, dan mengoptimalkan media sosial untuk promosi pelayanan. Praktik signifikansi terkait pola komunikasi dengan pengguna referensi di era digital lebih efektif menggunakan email dan chatting di aplikasi WhatsApp.
\end{abstract}

Kata Kunci: Pelayanan referensi; Perpustakaan akademik; Transformasi pelayanan referensi; Praktik signifikasi 


\section{PENDAHULUAN}

Sejak tahun 2000-an secara bertahap pelayanan referensi di Perpustakaan Universitas Indonesia (UI) mengalami transformasi dari pelayanan klasik ke pelayanan digital. Pelayanan referensi klasik merupakan pelayanan pemberian bantuan baik informasi maupun literatur secara tatap muka antara pustakawan dan pengguna. Pengguna dan pustakawan bertemu secara fisik di perpustakaan yang terbatas pada jam operasional perpustakaan. Pustakawan melakukan wawancara intensif dan berusaha memahami kebutuhan informasi pengguna agar tidak ada kesalahpahaman atas informasi yang dibutuhkan oleh pengguna. Pengguna dapat menanyakan permasalahan yang berhubungan dengan penelitiannya. Pengguna dan pustakawan dapat saling menangkap mimik, gestur, dan isyarat bahasa tubuh lainnya selama wawancara atau diskusi berlangsung.

Menurut Kaur and Gaur (2017), perpustakaan akademik sebagai pusat pengajaran, pembelajaran, dan kegiatan penelitian yang bertujuan untuk memuaskan kebutuhan informasi pengguna dan dilakukan melalui koleksi yang memadai. Di lingkungan digital, kebijakan pengembangan koleksi mengalami transformasi metaforis karena keanekaragaman sumber daya digital yang mudah telah tersedia melalui internet. Adapun penyediaan sarana pelayanan digital bertujuan untuk mempermudah pengguna dalam mendapatkan akses ke sumber informasi. Pengguna di Perpustakaan UI misalnya dapat melakukan penelusuran kapan saja melalui link http://lib.ui.ac.id/opac/ui/. Pustakawan juga dapat melayani pengguna secara online melalui email, chat, Facebook dan Twittter. Pengguna dapat mengajukan pertanyaan atau menghubungi pustakawan melalui alamat email refdesk.lib@ui.ac.id, atau melalui akun Facebook.com/perpustakaan-universitasindonesia, Twitter dengan akun @ui-library, serta chatting dengan akun chatref.ui.ac.id.

Berdasarkan pengamatan penulis di lapangan, kondisi Perpustakaan UI menunjukkan bahwa membangun dan memelihara pelayanan referensi digital memiliki banyak tantangan. Banyak perpustakaan yang telah berjuang untuk mempertahankan kualitas pelayanan secara konsisten untuk pengguna dalam menanggapi tumpukan pertanyaan dari waktu ke waktu. Tantangan itu di antaranya pelayanan referensi digital asynchronous, terutama email di mana pengguna tidak mendapatkan respons yang cepat dari pustakawan. Tantangan dari sisi pustakawan adalah mereka tidak mempunyai kesempatan untuk melakukan wawancara yang sangat krusial dalam menentukan kebutuhan informasi pengguna karena pengguna terkadang bertanya dengan frase yang tidak lengkap (Nicholas, 2011). Hal ini sangat rentan terjadinya salah penafsiran dari pustakawan dalam memahami pernyataan dan kebutuhan informasi pengguna. Lebih jauh lagi, wawancara referensi yang dilakukan melalui email dan website tidak secara real time. Pustakawan dalam menjawab pertanyaan memiliki konsentrasi waktu lebih lama daripada menjawab pertanyaan langsung yang diajukan diri sendiri melalui telepon, chat, atau videoconferencing.

Pustakawan mengalami perubahan dalam menjalankan pelayanan referensi sehingga hal ini cukup menarik untuk dikaji, khususnya bagaimana pustakawan menyikapi dan memaknai perubahan tersebut bagi diri dan profesi. Signifikasi 
(proses pemahaman) ini akan berdampak pada sikap mereka dalam menerima perubahan dan menjalankan pelayanan. Signifikasi diartikan sebagai proses pembentukan makna melalui sistem tanda atau sistem penandaan (Barker et al., 2012).

Sesuai rujukan ini, ketika kita berbicara mengenai sistem signifikasi maka kita dapat berbicara mengenai dua sistem, yaitu denotasi dan konotasi. Denotasi adalah level makna deskriptif dan literal yang secara virtual dimiliki semua anggota suatu kebudayaan. Konotasi pada level kedua, makna terbentuk dengan mengaitkan penanda dengan aspek kultural yang lebih luas, di antaranya keyakinan, sikap, kerangka kerja, dan ideologi suatu formasi sosial. Kemudian makna sebagai persoalan asosiasi tanda dengan kode makna kultural lainnya. Konotasi dinaturalkan sebagai sesuatu yang hegemonik, artinya diterima sebagai sesuatu yang normal dan alami. Maka konotasi bertindak sebagai peta makna konseptual, di mana seseorang dapat memahami dunia yang dikatakan sebagai mitos.

Sesuai kajian budaya, konsep mitos lebih merujuk pada naturalisasi makna konotatif, sesuatu yang kurang lebih mirip dengan makna istilah ideologi. Jadi, mitos membuat suatu pandangan dunia yang khas dan tampaknya tidak bisa diganggu gugat karena bersumber dari alam atau pemberian Tuhan (Barker, 2014). Order of signification dalam penelitian ini diaplikasikan untuk membaca praktik signifikasi komunitas pengguna dan pustakawan atas transformasi pelayanan referensi yang berlangsung di Perpustakaan UI.

Pustakawan referensi sebagai intermediary antara koleksi perpustakaan dengan pengguna berasal dari kategori immigrant, yang merupakan entitas berbeda dengan komunitas pengguna. Perbedaan ini tidak terlepas dari konteks kultural, nilai sosial, strata pendidikan, dan level ekonomi. Praktik signifikasi pengguna dan pustakawan atas perubahan konsep pelayanan referensi ke digitalisasi berkaitan erat dengan berbagai hal tersebut.

Menurut Das (2015), kehadiran internet membuat perpustakaan ada di dunia maya dan sedang beradaptasi ke teknologi baru. Pustakawan referensi profesional perlu menjangkau dan membantu pengguna dengan mengoptimalkan teknologi. Pelayanan referensi digital telah memperkenalkan peluang baru sebagai tantangan baru bagi pustakawan atau profesional informasi, pengguna, dan vendor.

Pustakawan dan profesional informasi harus menerima tantangan, mencari ide baru, dan metode tepat untuk meningkatkan dalam penyediaan pelayanan referensi yang lebih baik dan modern. Penguasaan teknologi dalam digitalisasi pelayanan referensi tidak lepas dari konteks kultural pengguna yang membentuk perilaku dalam menggunakan teknologi. Hal ini memiliki asumsi dasar bahwa perilaku dalam menggunakan teknologi tidak lepas dari konteks sosiokultural pengguna. Fenomena dalam penelitian ini yaitu mengenai transformasi pelayanan referensi di Perpustakaan UI. Sesuai fenomena ini, maka pertanyaan penelitian ini adalah bagaimana praktik signifikasi komunitas pengguna dan pustakawan atas transformasi pelayanan referensi klasik ke digital di Perpustakaan UI. Topik praktik signifikasi jarang dikaji oleh pustakawan apalagi yang berkaitan dengan transformasi pelayanan, 
khususnya pelayanan referensi. Kajian terhadap pelayanan referensi umumnya menyangkut perubahan perilaku informasi pengguna, bukan pada pustakawan memaknakan pelayanan referensi. Maka penelitian ini bertujuan untuk mengetahui praktik signifikasi transformasi pelayanan referensi di Perpustakaan UI sehingga penelitian dapat memberikan kontribusi baru di bidang kepustakawanan.

\section{METODE PENELITIAN}

Penelitian ini menggunakan pendekatan kualitatif melalui metode penelitian fenomenologi yang dinarasikan secara deskriptif. Adapun peneliti dalam menganalisis hasil penelitian menggunakan teori semiotika karena mendiskusikan signifikansi. Pengumpulan data dilakukan melalui kegiatan observasi dan wawancara. Setelah data terkumpul, langkah berikutnya adalah menganalisis data. Salah satu sumber data berasal dari subjek penelitian atau informan. Teknik dalam penentuan informan menggunakan purposive sampling, yakni informan yang dipilih sesuai kriteria penelitian. Informan penelitian adalah pengguna dan pustakawan pelayanan referensi di Perpustakaan UI. Pengguna adalah sivitas akademika yang menggunakan pelayanan referensi Perpustakaan UI, khususnya dari kelompok Pascasarjana dan dosen (UI dan non UI). Komunitas pengguna sebagai informan pada tabel 1, mewakili beragam kriteria yaitu, gender, usia, dan jenjang pendidikan. Informan kedua yaitu pustakawan pada tabel 2, yang dipilih berdasarkan kriteria pendidikan yaitu pascasarjana dan pengalaman kerja yang cukup lama sebagai staf Perpustakaan UI.

Kedua informan di atas memiliki kisikisi pertanyaan yang tertera pada tabel 3 .
Pertanyaan kepada pengguna meliputi tujuan penggunaan electronic resources, jumlah akses, sumber literatur, pemilihan pelayanan, dan harapan pelayanan perpustakaan ke depan. Adapun pertanyaan kepada pustakawan di antaranya mengenai tingkat kunjungan pelayanan, program peningkatan pelayanan, tantangan pelaksanaan pelayanan, makna pelayanan referensi, dan harapan pelayanan perpustakaan. Adapun semua pertanyaan ini menghasilkan data dan informasi yang kemudian diberikan kode (open coding, axial coding, selective coding), dikelompokkan, dihubungkan, dan dianalisis dari sudut pandang teori yang relevan hingga mendapatkan konsep yang dapat dijadikan jawaban atas pertanyaan penelitian. Secara rinci tahapan analisis data dalam penelitian ini dapat dilihat pada gambar 1 .

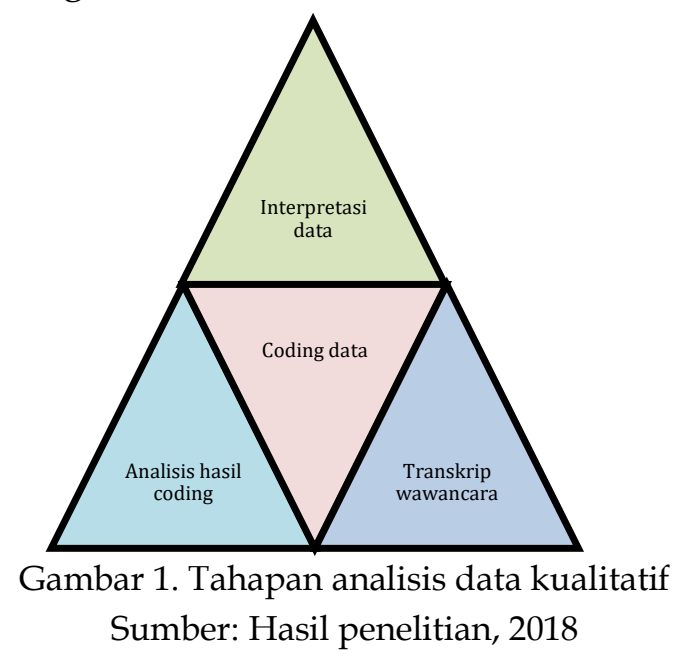

\section{HASIL DAN PEMBAHASAN}

Peneliti melakukan analisis data berdasarkan hasil wawancara terhadap dua kelompok informan, yakni pengguna pelayanan referensi dan pustakawan referensi. Setelah melalui proses transkrip wawancara dan open coding, analisis hasil coding menghasilkan tema sebagai berikut.

Tema pertama, mengenai perpustakaan berbasis digital. Daryono 
(2016) mengatakan bahwa Teknologi Informasi dan Komunikasi (TIK) telah berkembang pesat di bidang kehidupan manusia, termasuk dunia perpustakaan. Semua orang membayangkan dampak atau masa depan dari keajaiban teknologi, bahwa konsumsi kertas di perkantoran akan semakin sedikit (paperless) dan hubungan antar manusia akan semakin renggang karena makin tingginya interaksi antara manusia dengan komputer.

"Pada faktanya, World Wide Web (WWW) masih belum menggantikan media cetak. Kertas makin meningkat karena sebagian besar orang mencetak artikel yang hendak dibaca. Industri majalah pun semakin subur. Dunia digital ternyata juga belum mampu membuat manusia sebagai mesin mekanis dan terisolasi dalam dunia mesin. Komunitas pembelajar makin banyak terbentuk dengan minat yang sama dan saling berbagai pengetahuan dalam media elektronik, seperti mailing list dan chat room. Di sisi lain, akses mendapatkan informasi semakin mudah sehingga muncul buzzword baru seperti ledakan informasi (information explosion). Tapi sebagian orang mengatakan bahwa sekarang bukanlah ledakan informasi tetapi hanya ledakan non informasi atau sesuatu yang tidak memberikan informasi apa-apa (stuff that simply doesn't inform). Informasi saja tanpa alat dan pola yang tepat tidak akan berguna. Informasi saja tidak cukup. Website tidak akan memecahkan masalah yang dihadapi manusia, tetapi manusia yang terus belajar yang mampu memanfaatkan informasi dan memecahkan masalahnya sendiri" (Daryono, 2016)
Sesuai rujukan ini, pembelajaran menggunakan informasi sangat penting dilakukan. Hasil akhir pemanfaatan TI bagi manusia dapat memudahkan temu kembali informasi, menciptakan lingkungan pembelajaran (learning environment), dan membuat manusia yang terlibat di dalamnya sebagai manusia pembelajar seumur hidup. Maka konsep knowledge management dan information management lebih populer.

Kondisi ini pun ada di perpustakaan akademik, di mana TI dimanfaatkan dalam operasional dan pendukung konsep pelayanan. Sebagian besar pengguna layanan di perguruan tinggi berasal dari kelompok pascasarjana dan dosen yang bukan termasuk digital native. Pengguna perlu adaptasi dalam menggunakan teknologi. Maka, pelayanan perpustakaan diharapkan dapat mengakomodir berbagai karakter yang ada di perguruan tinggi.

Electronic resource yang dilanggan UI disambut positif dan antusias oleh pengguna pelayanan rujukan karena koleksinya cukup lengkap dan sangat membantu kelancaran perkuliahan dan pengajaran. Demikian juga layanan yang diberikan pustakawan sangat membantu pengguna. Electronic Resources Delivery Services (EDS) merupakan salah satu pelayanan andalan Perpustakaan UI khususnya pengguna dari kalangan profesor. Ide pelayanan ini muncul dari kesadaran bahwa para guru besar tidak memiliki waktu banyak untuk menelusur karena aktivitas mereka yang cukup padat dalam pengajaran dan penelitian.

Untuk itu, pustakawan harus membantu menyediakan literatur sesuai subjek minat para profesor yang berbasis digital, melalui email. Para profesor tidak perlu berkunjung ke perpustakaan. Mereka dapat mengontak pustakawan 
terlebih dahulu dan menunggu kiriman email dari pustakawan. Setelah itu, para profesor dapat berkomunikasi lebih intens melalui email dengan pustakawan. Sejak diluncurkan awal 2016, maka EDS mendapatkan respons cukup bagus dari para profesor.

Pelayanan perpustakaan berbasis digital bukan sesuatu yang baru di dunia kepustakawanan. Sejak teknologi masuk ke perpustakaan melalui sistem otomasi (lebih dari 10 tahun yang lalu), perpustakaan secara perlahan beradaptasi dengan perkembangan TIK. Saat konsep Library 2.0 muncul, bahkan sekarang telah hadir Library 4.0, yang makin mengukuhkan bahwa pelayanan perpustakaan dituntut berbasis teknologi (digital). Pelayanan referensi di Perpustakaan UI pun berusaha mengimplementasikan konsep ini dalam bentuk program. Menurut informan G, apa yang dilakukan Perpustakaan UI saat ini masih jauh dari yang diharapkan dibandingkan dengan yang sudah ada di luar negeri. Sayangnya, informan G tidak menjelaskan konsep seperti apa yang sudah pernah dilihat dan target yang akan dilakukan di layanan referensi Perpustakaan UI.

Informan G memberikan penjelasan lebih detail mengenai target atau level yang diharapkan sehingga dapat diterjemahkan dalam kegiatan sehari-hari di pelayanan rujukan. Menurut informan G pun, Perpustakaan UI telah melakukan evaluasi terhadap pelayanan referensi. Hasil evaluasi menyatakan bahwa jumlah kunjungan ke pelayanan referensi masih sangat rendah. Maka pustakawan akan melakukan pengembangan dengan berbagai program kegiatan sesuai perkembangan TIK dan tren electronic resources.
Adapun menurut informan E, perpustakaan memerlukan konsep dan kebijakan yang jelas mengenai operasional pelayanan referensi sebagai acuan bagi pustakawan dalam melaksanakan tugasnya. Informan C pun menambahkan bahwa konsep yang berjalan saat ini sudah cukup bagus dengan hadirnya pelatihan literasi informasi. Sementara itu, menurut informan A, fokus kegiatan pelayanan referensi harus memfokuskan pada penggunaan pemanfaatan online database yang dilanggan UI. Program online database sendiri telah berjalan sejak lama dan sekarang segmen pasarnya difokuskan pada staf pengajar.

Selain itu, saat ini pelayanan referensi Perpustakaan UI dari sisi pengguna di era digital cukup baik dari segi content dan pelayanan yang diberikan pustakawan. Kualitas pelayanan sendiri dipengaruhi banyak faktor, antara lain Sumber Daya Manusia (SDM), fasilitas, dan sistem yang dirancang. Pelayanan referensi Perpustakaan UI dinilai pengguna cukup baik yang dipengaruhi kualitas SDM yang baik. Walaupun demikian, Perpustakaan UI tidak dapat berpuas diri. Perpustakaan tetap harus melakukan pembenahan untuk menghadapi perubahan dan perkembangan TIK. Informan dari kelompok pustakawan sendiri memiliki harapan bahwa pelayanan referensi perlu diketahui pimpinan.

Pustakawan pun harus menilai lokasi pelayanan sebagai sesuatu yang krusial. Lokasi pelayanan yang tidak strategis mengakibatkan pengguna tidak dapat menjangkau pelayanan dengan mudah. Pustakawan berharap pimpinan dapat merealisasikan konsep yang pernah ditawarkan, yakni mendesain meja pelayanan referensi, seperti customer service di bank. Berdasarkan hal ini, 
evaluasi dan inovasi sabagai dua kata kunci penting bagi pengembangan layanan referensi di era digital supaya perpustakaan tidak tertinggal sesuai perkembangan teknologi. Layanan referensi yang berkualitas dapat diwujudkan dengan rancangan yang baik dan matang mulai dari segi SDM, konsep pelayanan, kebijakan pelayanan, dan fasilitas yang mendukung. Pustakawan di era digital saat ini memiliki banyak peluang yang dapat dilakukan untuk mengembangkan sistem layanan referensi dengan mengoptimalkan TIK.

Pustakawan pelayanan referensi di perguruan tinggi berfungsi sebagai subjek spesialis di mana mereka melayani pengguna sesuai bidang keilmuan. Untuk itu, pustakawan pelayanan referensi disyaratkan memiliki minimal pendidikan program Magister (S-2) dan latar belakang keilmuan ilmu perpustakaan dan informasi. Hal ini pun secara tidak tersurat berlaku di Perpustakaan UI. Walaupun demikian, pustakawan referensi yang bertugas dalam praktiknya adalah pustakawan yang memiliki pendidikan magister dengan latar belakang keilmuan yang berbeda, misalnya pendidikan program Sarjana (S-1) dari Fakultas Ilmu Sosial dan Politik sedangkan Magister (S2) dari Jurusan Ilmu Perpustakaan dan Informasi.

Tema kedua mengenai perluasan akses. Salah satu manfaat implementasi TIK di perpustakaan adalah kemudahan akses resources yang tersedia di database sebuah perpustakaan tanpa harus mengunjungi perpustakaan secara langsung. Persoalan akses perpustakaan merupakan kunci utama dari keberhasilan sebuah perpustakaan digital. Menurut Han, Huang, Li, and Ren (2016), penilaian risiko keamanan informasi perpustakaan digital berkaitan dengan empat masalah, di antaranya keamanan informasi perpustakaan tradisional, keamanan informasi perpustakaan digital, standar dan spesifikasi manajemen keamanan informasi perpustakaan digital, dan metode penilaian risiko keamanan informasi.

Maidabino and Zainab (2012) mengulas parameter keamanan perpustakaan dan mengembangkan instrumen yang komprehensif dalam manajemen dan penilaian keamanan perpustakaan. Sementara itu, Ismail and Zainab (2013) mengusulkan model evaluasi keamanan sistem informasi perpustakaan, yang terdiri dari lima komponen, nyaitu dasar keamanan teknologi, kebijakan keamanan informasi, prosedur dan kontrol, alat administrasi, metode dan penciptaan kesadaran. Abioye and Rasaki (2013) pun menambahkan bahwa dalam pengumpulan data untuk menyelidiki tantangan keamanan di perpustakaan universitas Nigeria Barat Daya telah menggunakan kuesioner dan wawancara. Gressel (2014) malam menekankan perlunya melindungi informasi pengguna sistem perpustakaan. Semua penelitian terdahulu ini berbeda satu sama lain. Semua penelitian ini memiliki kesamaan dalam dukungan terhadap masalah keamanan informasi perpustakaan yang melibatkan teknologi, manajemen, pengguna dan pemangku kepentingan, dan penilaian manajemen keselamatan informasi perpustakaan yang harus dianalisis secara holistik oleh pustakawan.

Jika dikaji lebih cermat, semua indikator di atas bermuara pada kecepatan dan kemudahan akses sesuai content atau resources di perpustakaan. Semua jenis sistem yang dikembangkan perpustakaan 
bertujuan untuk menyediakan akses yang cepat dan mudah. Resources yang jumlahnya banyak apabila tidak dapat diakses dengan mudah maka resources tersebut tidak akan bermanfaat secara optimal. Untuk itu, persoalan akses dalam konteks layanan digital sebagai salah satu fokus utama pustakawan.

Perpustakaan UI sendiri telah menyediakan berbagai akses ke database yang dimiliki melalui website www.lib.ui.ac.id dan sistem remote. Semua akses ini disediakan untuk mengakomodir kebutuhan pengguna yang beragam. Pengguna yang sedang melakukan aktivitas di kampus dapat mengakses langsung koleksi sedangkan bagi pengguna yang berada di luar area kampus dapat mengakses melalui website. Pengguna pun khusus dapat mengakses electronic resources yang dilanggan menggunakan jaringan Perpustakaan UI dan melalui sistem remote. Sistem ini memudahkan pengguna untuk tetap terhubung dengan electronic resources walaupun berada di luar area kampus.

Selain itu, Perpustakaan UI menyediakan fasilitas federated search yakni menu untuk masuk ke semua online journal yang dilanggan dari satu pintu. Pengguna melalui menu federated search dapat langsung mengakses semua database yang dilanggan untuk mendapatkan literatur sesuai keyword yang diketik dalam kotak pencarian. Sistem remote dapat digunakan pengguna untuk mengakses electronic resources yang dilanggan Perpustakaan UI, namun berdasarkan pengalaman para informan, akses melalui remote seringkali bermasalah.

Pustakawan terkadang mengeluhkan sistem remote yang sering bermasalah. Pengguna yang mengeluhkan akses sistem remote yang bermasalah mengirimkan pesan keluhan melalui email. Berdasarkan hal ini, penyediaan akses electronic resources melalui sistem remote sangat membantu, namun kapasitas atau sarana yang disediakan belum optimal. Perpustakaan UI perlu menyikapi dengan cermat masalah akses electronic resources melalui sistem remote mengingat akses tersebut merupakan andalan bagi pengguna yang tidak dapat berkunjung ke perpustakaan. Akses melalui sistem remote telah melibatkan unit lain di universitas khususnya bagian Direktorat Sistem Teknologi Informasi (DSTI) UI. Server Perpustakaan UI sendiri berada di domain DSTI. Maka, Perpustakaan UI perlu menjalin koordinasi yang baik dengan DSTI agar semua pelayanan yang berbasis akses online dapat berjalan lancar. Selain itu, universitas pun perlu menyepakati kebijakan yang terkait pengelolaan server agar selalu on dan mekanisme penanganan keluhan dari pengguna mengenai akses ke server.

Sementara itu, pengguna layanan rujukan menghadapi kendala utama gangguan akses dari luar jaringan Perpustakaan UI, yakni akses melalui remote. Pengguna mengakui bahwa ketersediaan akses melalui remote ini sebetulnya sangat membantu namun seringkali bermasalah ketika electronic resources tidak dapat diakses atau tersambung karena masalah jaringan. Keluhan mengenai sistem remote ternyata dikeluhkan juga oleh pengguna sebagai informan dan pengguna non informan.

Tema ketiga mengenai kebijakan terkait pelayanan rujukan dalam beberapa hal, antara lain SDM, teknologi, sistem pelayanan, sarana/fasilitas, dan peraturan tentang pelayanan. Pustakawan referensi di perpustakaan akademik memang dituntut untuk setara dengan pengguna 
yang sedang dilayani. Pendidikan pustakawan referensi di negara yang lebih maju minimal bergelar Master (S-2) bahkan Doktor (S-3). Latar belakang keilmuan ini penting mengingat pengguna yang dilayani berasal dari latar belakang pendidikan tinggi. Selain itu, pustakawan pun perlu memiliki rasa percaya diri ketika diskusi dengan pengguna dari kelompok pascasarjana.

Informan $G$ mengatakan bahwa di universitas telah tersedia kebijakan tentang aturan kerja yang harus diikuti oleh pustakawan referensi. Hal ini diperjelas informan A, bahwa kelancaran semua operasional pelayanan tergantung pada tata cara pelaksanaannya. Maka, sebaiknya perpustakaan memiliki Standar Operasional Prosedur (SOP) yang dijadikan acuan dan pustakawan memahaminya. Senada dengan informan A, informan B, C, E, dan F pun mengeluhkan hal yang sama bahwa di perpustakaan belum ada kebijakan tertulis terkait pelaksanaan pelayanan referensi. Acuan tertulis ini diperlukan khususnya ketika melayani pengguna dari luar UI. Pustakawan memerlukan legalitas kebijakan, contohnya berkaitan dengan biaya. Pengguna dari luar UI memang tidak memiliki hak akses ke electronic resources yang dilanggan UI sehingga mereka memerlukan online journal yang tidak dikenakan biaya. Sementara itu, informan G bercerita bahwa peraturan terkait pelayanan dan pengguna telah ada namun masih terbatas untuk khusus pengguna UI. Padahal pustakawan banyak mengeluhkan longgarnya peraturan untuk pengguna non UI.

Tema keempat ialah pengoptimalan media sosial. Perpustakaan UI sejak 2005 telah merintis pelayanan referensi melalui email. Pelayanan ini diadakan untuk melihat perkembangan komunikasi antara pustakawan dengan pengguna yang lebih banyak menggunakan email. Pelayanan ini tetap berjalan hingga saat ini dan sebagai salah satu andalan pustakawan dalam menjangkau pengguna dengan cara praktis. Sebagian informan menilai layanan melalui email dinilai paling efektif. Adapun informan lain malah lebih memilih WhatsApp karena dinilai lebih simpel.

Informan AP menyatakan bahwa perubahan pola komunikasi dalam pelayanan dari konvensional ke online dirasakan efisien dan efektif melalui email. Begitu pun dengan informan WU. Kedua informan ini sebelumnya tidak mengetahui bahwa ada pelayanan referensi melalui email sehingga mereka lebih sering datang langsung ke perpustakaan. Sementara informan MS, memilih berkunjung langsung dan berdiskusi dengan pustakawan. Hal ini bagi informan MS, ada kepuasan tersendiri ketika datang berkunjung langsung dan bertemu dengan pustakawan, misalnya dapat bertukar pikiran dan mendapatkan jawaban langsung mengenai masalah akses electronic resources.

Bagi pengguna dan pustakawan di pelayanan referensi, komunikasi melalui email dan WhatsApp nampaknya sangat membantu. Pustakawan menilai bahwa media komunikasi melalui email sangat efektif untuk menjangkau pengguna di pelayanan referensi. Maka, seiring perkembangan teknologi, banyak perpustakaan yang sudah maju mengembangkan berbagai aplikasi berbasis chatting untuk pelayanan referensi.

Perpustakaan UI sempat mengembangkan aplikasi ini, bernama 
Library Chat yang bertujuan pengguna dapat terhubung ke pustakawan kapan saja dan melakukan komunikasi secara real time. Ketika pengguna berkomuniksi melalui email, komunikasi tidak secara real time karena ada jeda waktu pengguna saat mengirim email sampai muncul balasan. Adapun aplikasi Library Chat memungkinkan pengguna untuk langsung berkomunikasi dengan pustakawan secara online (real time). Namun program Library Chat tidak dapat berjalan dengan baik. Pustakawan belum mendapatkan kompensasi mengenai pengganti jadwal kerja yang digunakan pada program Library Chat. Hal ini merupakan persoalan administratif, di mana jadwal kerja yang dihabiskan pustakawan dari program ini belum dapat terbaca oleh sistem kehadiran. Jadwal kerja program Library Chat ialah penuh waktu namun sistem presensi pegawai belum dapat melakukan verifikasi data kehadiran. Sistem dari program ini belum terintegrasi dengan sistem presensi pegawai.

Aplikasi layanan perpustakaan berbasis chat memang sedang banyak dikembangkan di berbagai lembaga, contohnya Perpustakaan Nasional Republik Indonesia meluncurkan aplikasi iPusnas atau Pemerintahan Provinsi DKI Jakarta meluncurkan aplikasi iJakarta. Aplikasi seperti ini dikembangkan untuk memudahkan pengguna agar dapat menjangkau layanan sebuah lembaga. Hal ini senada dengan pernyataan informan B, C, dan F, yang menyatakan bahwa sekarang sudah memasuki era aplikasi. Layanan perpustakaan khususnya layanan referensi telah banyak menggunakan aplikasi, di mana pengguna dan pustakawan dapat langsung install di telepon pintar (smartphone). Para informan dari pustakawan pelayanan referensi pun mengharapkan Perpustakaan UI dapat mengembangkan aplikasi tersebut.

Tema kelima adalah mengenai promosi. Peneliti menemukan hal menarik dari hasil wawancara di bagian awal tentang eksistensi pelayanan referensi. Para informan dari pustakawan cenderung menganggap bahwa pengguna saat ini sudah pintar menelusur sehingga tidak memerlukan bantuan pustakawan lagi sehingga kunjungan pengguna ke pelayanan referensi rendah. Di sisi lain, pengguna tidak mengetahui mengenai informasi pelayanan referensi tersebut. Pengguna baru mengetahui setelah mengikuti sosialisasi online journal atau informasi yang dikirim pustakawan melalui email. Pengguna justru sangat antusias ketika mengetahui keberadaan layanan referensi dan mengakui bahwa pengguna sangat membutuhkan pustakawan untuk penelusuran informasi. Strategi penelusuran dinilai pengguna sebagai domain pustakawan. Untuk itu, perpustakaan memerlukan promosi yang gencar agar semakin banyak pengguna yang memanfaatkan pelayanan referensi.

Kegiatan promosi kedua ialah peninjauan ulang lokasi layanan. Menurut informan $C$, posisi meja referensi saat ini yang berada di lantai 3 ternyata kurang strategis, tidak eye-catching, dan jauh dari jangkauan pengguna. Pustakawan memang tidak memfokuskan membenahi lokasi pelayanan referensi karena pelayanan sudah menggunakan email atau berbasis aplikasi chat. Maka lokasi sudah tidak relevan lagi untuk dipersoalkan. Namun, pustakawan perlu mempertimbangkan diri mengenai relokasi. Bagaimanapun juga, pustakawan perlu bekerja di tempat yang nyaman, tenang, dan kondusif. Semua faktor ini sebagai pertimbangan dalam penentuan lokasi pelayanan. 


\section{SIMPULAN}

Praktik

signifikasi komunitas pengguna dan pustakawan atas transformasi moda pelayanan referensi dalam penelitian ini menghasilkan simpulan bahwa era digital saat ini menuntut kompetensi pustakawan yang lebih spesifik (misalnya sebagai subjek spesialis), menghasilkan konsep digital library, memerlukan perluasan akses, menetapkan kebijakan yang relevan, dan mengoptimalkan media sosial untuk promosi pelayanan. Pengguna dan pustakawan memiliki kesamaan bahwa keterampilan menelusur sangat penting. Namun bagi pengguna, kompetensi menelusur dianggap sebagai wilayah pustakawan. Pengguna merasa tidak wajib memiliki kompetensi tersebut sepanjang ada pustakawan yang membantu memenuhi kebutuhan informasi mereka. Bagi pustakawan sendiri, harus dapat meningkatkan keterampilan menelusur informasi dan memiliki tugas untuk dapat memberikan edukasi kepada pengguna. Selain itu, pengguna pun harus memiliki keterampilan penelusuran Informasi untuk dirinya sendiri sebagai pembelajar yang mandiri. Praktik signifikansi kedua adalah pola komunikasi dengan pengguna referensi di era digital. Komunikasi dengan pengguna referensi lebih efektif menggunakan email dan chatting di WhatsApp yang dinilai lebih efisien dan praktis. Adapun perkembangan di dunia kepustakawanan terkait akses dan komunikasi dengan pengguna adalah tren aplikasi berbasis chatting. Pustakawan masih memiliki kendala dalam pengelolaan dan pemanfaatan pelayanan referensi, yakni belum ada kebijakan tertulis mengenai pelayanan referensi bagi pengguna Perpustakaan non UI yang menyulitkan operasional sehari-hari.
Sementara itu, pengguna dari Perpustakaan non UI memiliki kendala masih sulitnya akses literatur dari online database yang dilanggan Perpustakaan UI.

\section{DAFTAR PUSTAKA}

Abioye, A. A., \& Rasaki, O. E. (2013). Survey of security challenges in university libraries in Southwest Nigeria. Library \& Archival Security, 26(1-2), 1-13.

https://doi.org/10.1080/01960075.20 13.869078

Barker, K. R., Attridge, E., Bennett, J., Hiserman, T.,, Horne, A. S., Moody, D., .. \& Vaughn, P. (2012). The implementation of embedded quick response codes into library resources to improve service delivery. Journal of The Medical Library Association, 100(1), 68-71. https://doi.org/10.3163/15365050.100.1.013

Barker, R. (2014). The Gallant invalid: The Stage consumptive and the making of a Canadian myth. TRIC I RTAC: Theatre Research in Canada / Recherches Théâtrales Au Canada, 35(1), 69-88. Retrieved from

https://journals.lib.unb.ca/index.php /TRIC/article/view/21939/25435

Daryono. (2016). Meningkatkan kualitas layanan perpustakaan berbasis teknologi informasi. UNS Sebelas Maret University Library. Retrieved from https://library.uns.ac.id/meningkatk an-kualitas-layanan-perpustakaanberbasis-teknologi-informasi/

Das, A. K. (2015). An Overview of reference service for the digital era. An International Peer Reviewed Bilingual E-Journal of Library and Information Science, 2(3), 63-70. Retrieved from http:/ / www.klibjlis.com/2.3.5.pdf

Gressel, M. (2014). Are libraries doing 
enough to safeguard their patrons' digital privacy? The Serials Librarian, 67(2), 137-142.

https://doi.org/10.1080/0361526X.20 14.939324

Han, Z., Huang, S., Li, H., \& Ren, N. (2016). Risk assessment of digital library information security: A Case study. The Elctronic Library, 34(3), 471487. https://doi.org/10.1108/EL-092014-0158

Ismail, R., \& Zainab, A. N. (2013). Assessing the status of library information systems security. Journal of Librarianship and Information Science, 45(3), 232-247.

https:// doi.org/10.1177/09610006134 77676

Kaur, R., \& Gaur, R. (2017). Collection development in academic libraries with special reference to digital era. International Journal of Digital Library Services, 7(2), 107-114. Retrieved from http:/ /www.ijodls.in/uploads/3/6/ 0/3/3603729/12ijodls217.pdf

Maidabino, A. A., \& Zainab, A. N. (2012). A holistic approach to collection security implementation in university libraries. Library Collections, Acquisitions and Technical Services, 36(3-4), 107-120.

https://doi.org/10.1016/j.lcats.2012.0 5.004

Nicholas, P. (2011). Creating a digital reference agenda for academic libraries in Jamaica: An exploratory case study. Libri, 61(4), 258-280. https://doi.org/https:// doi.org/10.1 515/libr.2011.023 


\section{DAFTAR TABEL}

Tabel 1

Informan penelitian kelompok pemustaka

\begin{tabular}{|c|c|c|c|c|}
\hline No & Inisial & $\begin{array}{l}\text { Jenis kelamin \& } \\
\text { rentang usia }\end{array}$ & Lembaga & Profesi / jabatan \\
\hline 1 & IA & $\begin{array}{l}\text { Laki-laki } \\
\text { (40-45 tahun) }\end{array}$ & $\begin{array}{l}\text { President } \\
\text { University }\end{array}$ & Dosen \\
\hline 2 & $\mathrm{ZO}$ & $\begin{array}{l}\text { Perempuan } \\
\text { ( } 35-40 \text { tahun) }\end{array}$ & FKM UI & $\begin{array}{l}\text { Mahasiswa program doktor } \\
\text { (S-3) }\end{array}$ \\
\hline 3 & MS & $\begin{array}{l}\text { Laki-laki } \\
\text { (35-40 tahun) }\end{array}$ & FIK UI & $\begin{array}{l}\text { Mahasiswa program } \\
\text { magister (S-2) }\end{array}$ \\
\hline 4 & SU & $\begin{array}{l}\text { Laki-laki } \\
\text { (35-40 tahun) }\end{array}$ & $\begin{array}{l}\text { Universitas } \\
\text { Negeri Sebelas } \\
\text { Maret }\end{array}$ & $\begin{array}{l}\text { Mahasiswa program } \\
\text { magister (S-2) }\end{array}$ \\
\hline 5 & FR & $\begin{array}{l}\text { Laki-laki } \\
\text { (35-40 tahun) }\end{array}$ & $\begin{array}{l}\text { Universitas } \\
\text { Pertahanan }\end{array}$ & $\begin{array}{l}\text { Mahasiswa program } \\
\text { magister (S-2) }\end{array}$ \\
\hline 6 & $\mathrm{AM}$ & $\begin{array}{l}\text { Laki-laki } \\
\text { (50-55 tahun) }\end{array}$ & FISIP UI & Dosen/Profesor \\
\hline 7 & $\mathrm{AP}$ & $\begin{array}{l}\text { Laki-laki } \\
\text { (40-45 tahun) }\end{array}$ & FH UI & $\begin{array}{l}\text { Mahasiswa program doktor } \\
\text { (S-3) dan dosen di } \\
\text { perguruan tinggi swasta }\end{array}$ \\
\hline 8 & $\mathrm{CP}$ & $\begin{array}{l}\text { Laki-laki } \\
\text { (40-45 tahun) }\end{array}$ & FKM UI & $\begin{array}{l}\text { Mahasiswa program doktor } \\
\text { (S-3) }\end{array}$ \\
\hline 9 & $\mathrm{CW}$ & $\begin{array}{l}\text { Laki-laki } \\
\text { (45-50 tahun) }\end{array}$ & FISIP UI & Dosen/Profesor \\
\hline 10 & RF & $\begin{array}{l}\text { Perempuan } \\
\text { ( } 35-40 \text { tahun) }\end{array}$ & FISIP UI & Dosen \\
\hline 11 & GC & $\begin{array}{l}\text { Perempuan } \\
\text { ( } 35-40 \text { tahun) }\end{array}$ & $\begin{array}{l}\text { Fakultas } \\
\text { Psikologi UI }\end{array}$ & $\begin{array}{l}\text { Mahasiswa program doktor } \\
\text { (S-3) }\end{array}$ \\
\hline 12 & WU & $\begin{array}{l}\text { Perempuan } \\
\text { ( } 35-40 \text { tahun) }\end{array}$ & FH UI & $\begin{array}{l}\text { Mahasiswa program doktor } \\
\text { (S-3) }\end{array}$ \\
\hline 13 & $\mathrm{RH}$ & $\begin{array}{l}\text { Perempuan } \\
\text { (55-60 tahun) }\end{array}$ & FIB UI & Dosen/Profesor \\
\hline
\end{tabular}

Sumber: Hasil penelitian, 2018 
Tabel 2

Informan penelitian kelompok pustakawan

\begin{tabular}{lllll}
\hline No & Inisial & $\begin{array}{l}\text { Jenis Kelamin \& } \\
\text { rentang usia }\end{array}$ & Lembaga & Profesi / Jabatan \\
\hline 1 & A & $\begin{array}{l}\text { Laki-laki } \\
(50-55 \text { tahun })\end{array}$ & Layanan referensi & Pustakawan madya \\
2 & B & $\begin{array}{l}\text { Perempuan } \\
(45-50 \text { tahun })\end{array}$ & Layanan referensi & Pustakawan muda \\
3 & C & $\begin{array}{l}\text { Perempuan } \\
(45-50 \text { tahun })\end{array}$ & Layanan referensi & Pustakawan madya \\
4 & D & $\begin{array}{l}\text { Perempuan } \\
(50-55 \text { tahun })\end{array}$ & Layanan referensi & Pustakawan \\
5 & E & $\begin{array}{l}\text { Perempuan } \\
(45-50 \text { tahun })\end{array}$ & Layanan referensi & Pustakawan muda \\
6 & F & $\begin{array}{l}\text { Laki-laki } \\
(50-55 \text { tahun })\end{array}$ & Layanan referensi & Pustakawan muda \\
7 & G & $\begin{array}{l}\text { Perempuan } \\
(25-35)\end{array}$ & Layanan referensi & Pustakawan \\
\hline
\end{tabular}

Sumber: Hasil penelitian, 2018

Tabel 3

Kisi-kisi pertanyaan untuk informan

\begin{tabular}{|c|c|}
\hline Kisi-kisi pertanyaan untuk pustakawan & Kisi-kisi pertanyaan untuk pemustaka \\
\hline $\begin{array}{l}\text { 1) Bagaimana tingkat kunjungan pengguna pada } \\
\text { pelayanan referensi ini sendiri dan apa faktor } \\
\text { yang memengaruhi? }\end{array}$ & $\begin{array}{l}\text { 1. Untuk keperluan perkuliahan, pengajaran, dan } \\
\text { riset, sumber informasi apa yang paling sering } \\
\text { digunakan? Tercetak atau electronic resources? }\end{array}$ \\
\hline $\begin{array}{l}\text { 2) Bagaimana tingkat kunjungan pengguna } \\
\text { pada pelayanan referensi ini sendiri dan apa } \\
\text { faktor yang memengaruhi? }\end{array}$ & $\begin{array}{l}\text { 2. Untuk keperluan perkuliahan, pengajaran, dan } \\
\text { riset, sumber informasi apa yang paling sering } \\
\text { digunakan? Tercetak atau electronic resources? }\end{array}$ \\
\hline $\begin{array}{l}\text { 3) Apa yang perpustakaan lakukan untuk } \\
\text { meningkatkan pemanfaatan pelayanan } \\
\text { rujukan ini? }\end{array}$ & $\begin{array}{l}\text { 3. Sesering apa Anda mengakses electronic } \\
\text { resources? }\end{array}$ \\
\hline $\begin{array}{l}\text { 4) Bagaimana tantangan yang Saudara rasakan } \\
\text { dalam melaksanakan berbagai kegiatan pada } \\
\text { pelayanan referensi ini? }\end{array}$ & $\begin{array}{l}\text { 4. Anda mendapatkan literatur dari sumber mana } \\
\text { saja selain di perpustakaan? }\end{array}$ \\
\hline $\begin{array}{l}\text { 5) Bagaimana Saudara sebagai pustakawan } \\
\text { melihat dan memaknai perkembangan } \\
\text { pelayanan referensi saat ini? }\end{array}$ & $\begin{array}{l}\text { 5. Apakah Anda lebih suka pelayanan rujukan } \\
\text { konvensional (face to face) atau melalui email? } \\
\text { Apa alasannnya? }\end{array}$ \\
\hline $\begin{array}{l}\text { 6) Seperti apa harapan Saudara menghadapi } \\
\text { perkembangan pelayanan referensi ini ke } \\
\text { depan? }\end{array}$ & $\begin{array}{l}\text { 6. Bagaimana harapan Anda terhadap pelayanan } \\
\text { rujukan Perpustakaan UI? }\end{array}$ \\
\hline
\end{tabular}

